\title{
Insulin signaling and insulin response in subcutaneous and retroperitoneal adipose tissue in Holstein cows during the periparturient period
}

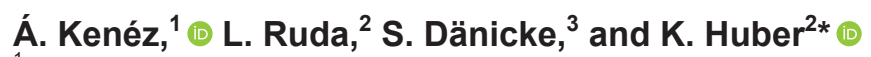 \\ ${ }^{1}$ Department of Infectious Diseases and Public Health, City University of Hong Kong, Hong Kong SAR \\ ${ }^{2}$ Institute of Animal Science, University of Hohenheim, Stuttgart 70599, Germany \\ ${ }^{3}$ Institute of Animal Nutrition, Friedrich-Loeffler-Institute (FLI), Federal Research Institute for Animal Health, Braunschweig 38116, Germany
}

\begin{abstract}
Adipose tissue response to endocrine stimuli, such as insulin, is crucial for metabolic adaptation at the onset of lactation in dairy cows. However, the exact molecular mechanisms behind this response are not well understood. Thus, the aim of this study was to determine the dynamics in protein expression and phosphorylation of key components in insulin signaling in subcutaneous (SCAT) and retroperitoneal (RPAT) adipose tissues of Holstein dairy cows. Furthermore, by ex vivo examinations, response to insulin was assessed in SCAT and RPAT at different time points during the periparturient period. Biopsy samples were taken $42 \mathrm{~d}$ prepartum, and 1, 21, and $100 \mathrm{~d}$ postpartum. Insulin and glucose concentrations were measured in blood serum in consecutive serum samples from $d-42$ until $d+100$. After parturition, the majority of the key components were downregulated in both adipose tissues but recovered by $d+100$. The extent of hormone-sensitive lipase phosphorylation increased postpartum and remained high throughout the experimental period. Strong differences in molecular response were observed between the 2 depots. The RPAT expressed a remarkably greater extent of AMP-activated kinase phosphorylation compared with SCAT, indicating that AMP-activated kinase as an energy sensor is highly active particularly in RPAT in times of energy scarcity. Consequently, this depot expressed a greater extent of hormone-sensitive lipase phosphorylation over the whole experimental period. Insulin response after parturition appeared to be greater in RPAT too, due to the significantly greater expression of the insulin receptor at $d+21$ and +100 . Although insulin concentrations in plasma were low postpartum, the depot-specific changes in molecular modulation of insulin signaling and insulin response suggested that both adipose tissue depots studied were contributing
\end{abstract}

Received April 28, 2019.

Accepted August 14, 2019.

*Corresponding author: korinna.huber@uni-hohenheim.de to the periparturient homeorhetic adaptation, although most likely to a different extent.

Key words: insulin signaling, subcutaneous adipose tissue, retroperitoneal adipose tissue, transition period

\section{INTRODUCTION}

Insulin secretion, circulating insulin concentrations, as well as insulin sensitivity and responsiveness of peripheral tissues, play key roles in nutrient partitioning in periparturient dairy cows. Dairy cows are known to develop a physiological state of decreased insulin sensitivity during peak lactation in times when the energy requirement and glucose demand of the mammary gland are the highest (De Koster and Opsomer, 2013). To facilitate channeling glucose toward the mammary gland instead of liver, adipose tissue, and skeletal muscle, serum insulin concentration typically decreases at the time of calving and remains low for at least 6 to $8 \mathrm{wk}$, as long as energy balance remains in the negative range (Drackley et al., 2001). Due to the high glucose requirement of the mammary gland serum glucose concentration is typically maintained on a low level, despite diminished insulin concentration (due to low pancreatic secretion) and the reduced glucose uptake by insulin-dependent peripheral tissues. This is an essential mechanism of the homeorhetic regulation that ensures the adaptation of metabolic pathways to the needs of lactation. However, a poor adaptation to negative energy balance is a risk factor for disease development (McArt et al., 2012; Ospina et al., 2013) and can trigger a state of metabolic imbalance, which contributes to compromised health, welfare, and production efficiency in dairy farming (Drackley, 1999; Ingvartsen et al., 2003).

In addition to considering serum insulin concentration, tissue level regulation of insulin sensitivity and insulin responsiveness are adequate means to assess extent of homeorhetic adaptation of insulin effect (Kahn, 1978). In this respect, sensitivity refers to the variation in insulin stimulus to reach the same biological re- 


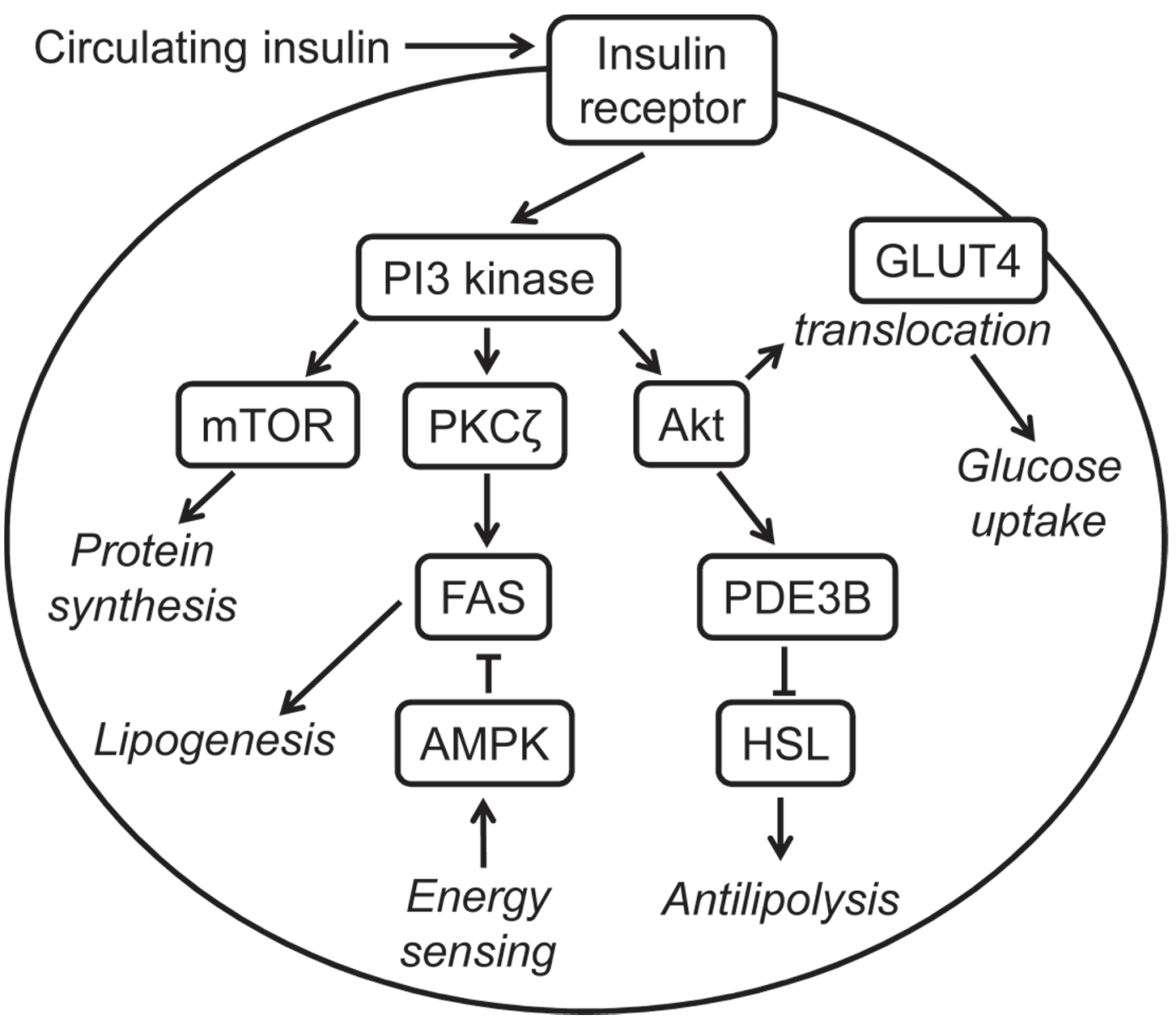

Figure 1. Target proteins of the insulin signaling pathway. The simplified scheme is based on Sasaki (2002). Insulin attachment to its receptor activates phosphatidylinositol 3-kinase (PI3K), which in turn activates mammalian target or rapamycin (mTOR), protein kinase zeta $(\mathrm{PKC} \zeta)$, and protein kinase B (Akt) by phosphorylation. mTOR modulates protein synthesis while PKC $\zeta$ stimulates lipogenesis by activating fatty acid synthase (FAS). However, FAS is inhibited by AMP-activated protein kinase (AMPK) that becomes phosphorylated when sensing cellular energy deficiency. The Akt phosphorylation promotes glucose transporter 4 (GLUT4) translocation into the cell membrane, stimulating glucose uptake. The Akt also activates phosphodiesterase 3B (PDE3B) phosphorylation, which inhibits lipolysis by decreasing hormone-sensitive lipase (HSL) phosphorylation.

sponse, whereas responsiveness refers to the variation of the biological response given to the same stimulus. In fact, these terms are closely interrelated, and they are determined by the cellular fine-tuning mechanisms consisting of downstream target elements of the insulin signaling pathway (White, 1997). Characteristics of the intracellular insulin signaling pathway were considered to be the same in ruminants as in other mammals (Sasaki, 2002). This controls various cellular processes including glucose uptake, lipid synthesis, lipolysis, and protein synthesis (Figure 1).

The major effect of a reduced insulin sensitivity and/or responsiveness in adipose tissues is a diminished anti-lipolytic effect, which is considered to be a primary reason for an aberrantly excessive lipid mobilization (Chilliard et al., 2000). This leads to a lipid overload of the liver, which can result in hepatic steatosis after exceeding the liver's oxidative capacities, and contributes to the metabolic disorders that commonly occur in high-yielding dairy cows during peak lactation (Ingvartsen, 2006). Further, lipid overload and associated oxidative stress were discussed as possible contributing factors to postpartum systemic inflammation (Bradford et al., 2015). However, excessive lipid mobilization might differentially originate from various adipose tissue depots such as subcutaneous and visceral adipose tissues. Different metabolic capacities have been associated with different adipose depots in human health and disease, with visceral depots considered to be generally more metabolically active (Holm et al., 2000). Similarly, variation between adipose depots was also found in dairy cows: Locher et al. (2011) and 
Kenéz et al. (2015) suggested greater lipolytic capacity for retroperitoneal adipose tissue (RPAT), compared with subcutaneous adipose tissue (SCAT), based on protein phosphorylation and in vitro lipolytic activity data. Ji et al. (2014) suggested that visceral adipose tissue might be more prone to release proinflammatory signals as an effect of overconditioning. Furthermore, ultrasonography-based predictions showed that abdominal adipose tissues (including retroperitoneal, omental, and mesenteric adipose tissues) together make up a roughly 3 times larger adipose mass than SCAT in German Holstein cows (Raschka et al., 2016; Ruda et al., 2019). Hence, abdominal adipose tissues, including RPAT, are suggested to have a larger contribution to adipose-derived nutrient metabolism than SCAT. However, the depot-specific molecular mechanisms driving adipose insulin sensitivity and responsiveness are not yet fully understood in detail in dairy cows.

We hypothesized that RPAT, as one of the abdominal adipose depots, undergoes more extensive adaptive changes during the periparturient period than SCAT, reflected by differences in protein expression and extent of phosphorylation in the insulin signaling cascade and by differences in insulin response. Hence, the objective of the study was to (1) identify and quantify key proteins of the insulin signaling pathway in dairy cattle adipose tissue samples in the period of $42 \mathrm{~d}$ prepartum to $100 \mathrm{~d}$ postpartum, (2) compare the dynamic protein expression and phosphorylation profile of subcutaneous and retroperitoneal adipose tissue, and (3) evaluate the insulin response in vitro in both adipose depots during the course of the periparturient period. Addressing these questions could help us gain a better understanding of how subcutaneous and retroperitoneal adipose tissues relate in terms of contribution to nutrient partitioning driven by insulin control in periparturient cows.

\section{MATERIALS AND METHODS}

\section{Animals and Sample Collection}

Adipose tissue biopsy samples were collected from 20 multiparous German Holstein cows in agreement with the German Animal Welfare Act and approved by the Lower Saxony State Office for Consumer Protection and Food Safety (LAVES; Oldenburg, Germany; permit number: 33.9-42502-04-11/0444). Cows used in this study were a subset of animals involved in a feeding trial to test the effect of energy density in the diet and niacin supplementation. Feeding, housing, and management of the animals were described in detail previously (Tienken et al., 2015). Animals selected for the present paper were balanced across nutritional treatment groups, even though the diet was assumed to have no effect on the investigated parameters since production performance and various physiological measures remained unaffected by the applied diet as shown in our previous papers (Kenéz et al., 2015, 2016; Tienken et al., 2015; Kinoshita et al., 2016b). Nevertheless, possible dietary effects were tested by ANOVA to confirm the absence of dietary influence. Cows were also balanced for BW, BCS, and milk yield of previous lactation to attenuate possible effects of different body condition (adiposity) and merit. Cows were kept in a freestall housing system at the Institute of Animal Nutrition, Federal Research Institute for Animal Health (Friedrich-Loeffler-Institute, Braunschweig, Germany), were clinically healthy, and were dried off 8 wk before expected parturition. The sampling period started when cows reached $42 \mathrm{~d}$ prepartum $(\mathrm{d}-42$; relative to expected day of calving) and lasted until $100 \mathrm{~d}$ postpartum $(d+100)$.

Biopsy samples of SCAT and RPAT were taken on $\mathrm{d}-42$ (retrospectively $41.8 \pm 3.2 \mathrm{~d}$ before the actual day of calving, mean $\pm \mathrm{SD}$ ), and on $\mathrm{d}+1$, $\mathrm{d}+21$, and $\mathrm{d}+100$ (actual days after calving), according to Locher et al. (2011). After preparation of the surgical field and local infiltration anesthesia induced with procaine (Procaine 2\%; Selectavet Dr. Otto Fischer GmbH, Weyarn-Holzolling, Germany), samples from adipose tissues were collected under antiseptic conditions. Samples of SCAT were collected from the region of the tail head, alternating on the left and the right side. Samples of RPAT were collected from the angle between the lumbar transversal processes and the iliac bone, alternating from the left and right flank. Tissue samples were trimmed of connective tissue and rinsed thoroughly in physiological saline solution to reduce blood contamination. One part of each tissue sample was immediately snap-frozen in liquid nitrogen and stored thereafter at $-80^{\circ} \mathrm{C}$ until Western blot analyses (all analyses were completed within $1 \mathrm{yr}$ ). Another part of each tissue sample was used to perform an in vitro insulin response assay.

In addition to adipose tissue biopsy samples, blood samples were collected on the following days relative to calving: $-42(-41.8 \pm 3.2$, mean $\pm \mathrm{SD}),-21(-20.6 \pm$ 2.3 , mean $\pm \mathrm{SD}),-10(-9.8 \pm 2.6$, mean $\pm \mathrm{SD}),+3$, $+7,+14,+21,+42,+63$, and +100 (actual days after calving). Blood samples were taken at $0730 \mathrm{~h}$ after a feed withdrawal of at least $2 \mathrm{~h}$, from a jugular vein into serum collection tubes. Samples were centrifuged at 2,000 $\times g$ for $10 \mathrm{~min}$ at room temperature and serum was stored at $-80^{\circ} \mathrm{C}$ until analysis. Serum glucose concentration was determined by an enzymatic endpoint colorimetric measurement (Greiner Diagnostic GmbH, 
Bahlingen, Germany) using an automatic analyzer system (Cobas Mira, F. Hoffmann-La Roche Ltd., Basel, Switzerland; intra- and interassay CV were 1.19 and $1.28 \%$, respectively) and serum insulin concentration was determined by a RIA validated for bovine insulin (IM3210, Immunotech, Beckman Coulter Inc., Brea, CA; intra- and interassay CV were 7.6 and $10.7 \%$, respectively).

\section{Quantification of Protein Expression and Extent of Phosphorylation in Adipose Tissues}

All SCAT and RPAT biopsy samples were prepared for Western blot analyses according to Kenéz et al. (2014). Briefly, tissue samples were homogenized with a FastPrep 24 instrument (MP Biomedicals, Santa Ana, CA) and proteins were extracted in a lysis buffer containing (in mmol/L) 50 HEPES (Carl Roth GmbH, Karlsruhe, Germany), 4 EGTA (Sigma-Aldrich, St. Louis, MO), 10 EDTA (Sigma-Aldrich), 100 ß-glycerol phosphate (Sigma-Aldrich), 15 sodium pyrophosphate (Sigma-Aldrich), 5 sodium orthovanadate (Sigma-Aldrich), 2.5 sodium fluoride (Sigma-Aldrich), 0.1\% Triton X-100 (Sigma-Aldrich), a protease inhibitor cocktail (CompleteMini, Roche Diagnostics GmbH, Mannheim, Germany), and a phosphatase inhibitor cocktail (PhosStop, Roche Diagnostics GmbH). Extracts were centrifuged at $10,000 \times g$ for $10 \mathrm{~min}$ at $4^{\circ} \mathrm{C}$, and aliquots of the supernatants were stored at $-20^{\circ} \mathrm{C}$ until electrophoresis. After determining the protein concentration using the Bradford method (Bradford Reagent, Serva Electrophoresis GmbH, Heidelberg, Germany), extracts were diluted to $0.5 \mathrm{mg}$ protein per $\mathrm{mL}$ in loading buffer [50 mmol/L of Tris-HCl (Sigma-Aldrich), 10\% glycerol (Sigma-Aldrich), 2\% SDS (Serva Electrophoresis $\mathrm{GmbH}$ ), $0.1 \%$ bromophenol blue (Sigma-Aldrich), $2 \%$ mercaptoethanol (Sigma-Aldrich); final concentrations] and heated at $95^{\circ} \mathrm{C}$ for $5 \mathrm{~min}$. Ten micrograms of protein per lane were separated by SDS-PAGE on $8.1 \%$ hand-cast gels by using a Mini-Protean TetraCell electrophoresis chamber attached to a PowerPac power supply (Bio-Rad Laboratories GmbH, München, Germany) and transferred to nitrocellulose membranes by semi-dry blotting using a TransBlot Turbo instrument (Bio-Rad Laboratories GmbH). Membranes were blocked in a PBS-based solution containing 5\% fat-free milk powder or 5\% BSA (Carl Roth $\mathrm{GmbH}$ ) and $0.1 \%$ Tween 20 (Sigma-Aldrich) for $1 \mathrm{~h}$ at room temperature.

Key proteins of the insulin signaling pathway were detected by incubating the membranes with the respective primary antibodies overnight at $4^{\circ} \mathrm{C}$ with gentle shaking. Details about the antibodies used, including reactivity against bovine target proteins and incuba- tion conditions, are given in Table 1. Beta-actin was quantified in all samples as a housekeeping protein for normalization (Sigma-Aldrich, A5441; 1:10,000 in PBS). Membranes were incubated with the matching secondary antibody (anti-rabbit IgG, horseradish peroxidaselinked, dilution 1:2,500, Cell Signaling Technology or anti-mouse IgG, peroxidase conjugate, dilution 1:50,000, Sigma-Aldrich) at room temperature for $1 \mathrm{~h}$. Immunodetection was performed by incubating the membranes with WesternBright Quantum or WesternBright Sirius (Advansta Corporation, Menlo Park, CA) and chemiluminescence was detected by a ChemiDoc XRS+ system (Bio-Rad Laboratories GmbH). Bands were quantified by densitometry using Image Lab 5.0 software (Bio-Rad Laboratories $\mathrm{GmbH}$ ). Finally, membranes were India ink stained (Pelikan PBS, Peine, Germany) to control equal loading. To ensure consistency between various membranes, the same pooled sample, mixed from equal amounts of SCAT and RPAT samples, was included on every membrane and band volume data were corrected for that value. Protein expression data were normalized for $\beta$-actin values and quantities of phosphorylated proteins were additionally normalized for total quantity of the corresponding protein detected in the same sample. These normalized values are referred to as "extent of phosphorylation" throughout the manuscript.

\section{In Vitro Insulin Response Assay}

Adipose tissue biopsy samples of all 20 cows at d $-42,+1,+21$, and +100 were processed in an in vitro insulin response assay to evaluate the anti-lipolytic effect provoked by a standard insulin treatment of physiological concentration. The assays were run on fresh tissue, immediately (within $5 \mathrm{~min}$ ) after taking the biopsy samples, according to McNamara and Hillers (1986) with modifications described below. Tissue samples (approximately $100 \mathrm{mg}$ ) were pre-incubated in Dulbecco's modified Eagle's medium (DMEM "low glucose, pyruvate"; Life Technologies Corporation, Paisley, UK) containing 2\% FA-free BSA (Sigma-Aldrich, St. Louis, MO) for $20 \mathrm{~min}$ at $37^{\circ} \mathrm{C}$ to diminish unspecific release of metabolites due to handling and cutting. Each sample was then incubated separately in $1 \mathrm{~mL}$ of freshly prepared DMEM containing 2\% FA-free BSA (incubation medium) for $90 \mathrm{~min}$ at $37^{\circ} \mathrm{C}$ with gentle shaking. Incubation medium was supplemented with the nonselective $\beta$-adrenoceptor agonist isoproterenol (Sigma-Aldrich) and bovine insulin (Akron Biotech, Boca Raton, FL) for the treatments as follows: (A) $1 \mu \mathrm{mol} / \mathrm{L}$ of isoproterenol and $0 \mathrm{mU} / \mathrm{L}$ of insulin for control stimulated lipolysis, and (B) $1 \mu \mathrm{mol} / \mathrm{L}$ of isoproterenol and $12 \mathrm{mU} / \mathrm{L}$ of insulin for registering 
KENÉZ ET AL.

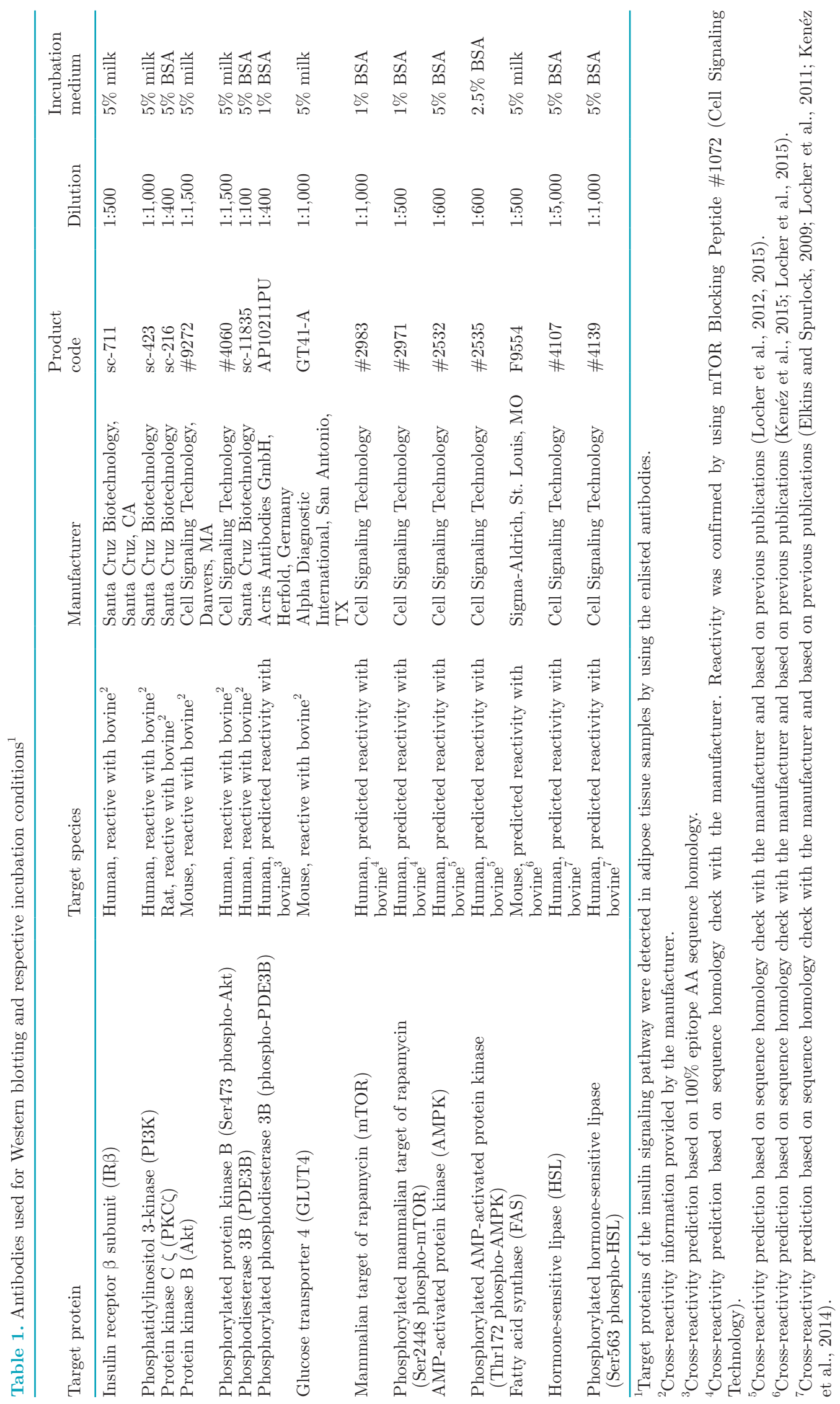




\section{A Serum glucose concentration}

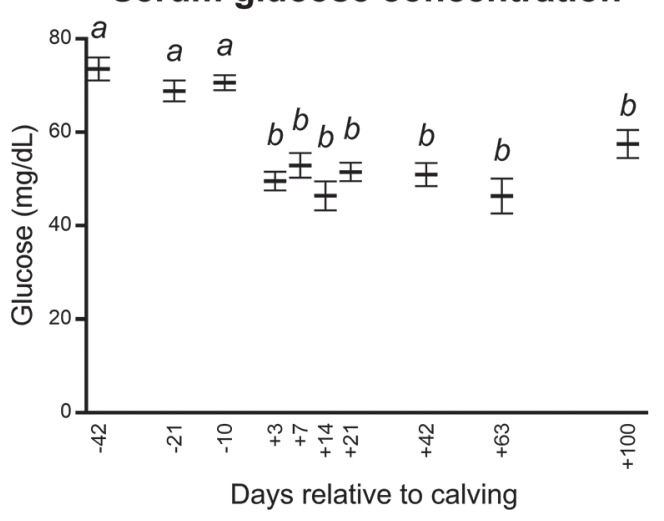

B

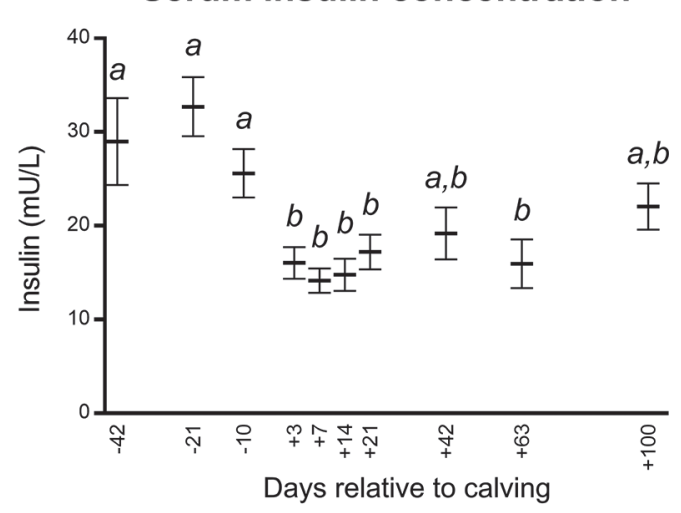

Figure 2. Serum glucose and insulin concentrations on different days during the study period. Different letters $(a, b)$ indicate significantly different values $(P \leq 0.05$; one-way repeated measures ANOVA). Means \pm SEM, $\mathrm{n}=20$.

anti-lipolytic effect of insulin. Incubation sets were performed in triplicate. Following incubation, tissue samples were briefly drained, snap-frozen in liquid nitrogen, and afterward stored at $-80^{\circ} \mathrm{C}$ until Western blot analyses (all analyses were completed within $1 \mathrm{yr}$ ).

Key proteins of the insulin signaling pathway, focusing on the anti-lipolytic downstream components, were quantified by Western blotting. Triplicates of incubated tissue samples were pooled, homogenized, and subjected to protein extraction as described above. Using the above-described antibodies, protein kinase B (Akt), phospho-Akt, hormone-sensitive lipase (HSL), and phospho-HSL were detected.

\section{Statistical Analysis}

Glucose and insulin concentration data were analyzed by one-way repeated-measures ANOVA for time-related differences. Data of protein expression and extent of phosphorylation in the untreated tissue were analyzed by 2-way repeated-measures ANOVA for the factor tissue (effect of different adipose depots) and the factor time (effect of different sampling days). Bonferroni's post-hoc test was performed for multiple comparisons between SCAT and RPAT on different days. Fold change values were calculated in the insulin response study by dividing protein expression and phosphorylation data of insulin-treated tissues by data of untreated tissues. Fold changes were tested by a one-sample $t$-test against the theoretical value of 1.0 for each sampling day for both SCAT and RPAT to evaluate whether insulin treatment caused any significant effect. All statistical analyses were performed in GraphPad Prism version 6.07 for Windows (GraphPad Software, La Jolla, CA). Statistical significance level was set at $P \leq 0.05$.

\section{RESULTS}

\section{Circulating Concentration of Glucose and Insulin}

Mean serum glucose and insulin concentrations on different days during the study are shown in Figure 2. Glucose and insulin concentrations dropped at the time of calving in the present cohort of cows and concentrations did not reach prepartum levels during the observed postpartum period of $100 \mathrm{~d}$, as published earlier (Kenéz et al., 2016).

\section{Insulin Signaling in SCAT and RPAT During the Periparturient Period}

The changes in expression and phosphorylation rate of key proteins of the insulin signaling pathway in SCAT and RPAT of cows during the periparturient period are shown in Figure 3. Quantification of the Western blot images (Supplemental Figure S1; https:/ /doi.org/10.3168/jds.2019-16873) and statistical analysis of the densitometric values allowed identification of several key proteins that were differentially expressed or phosphorylated in SCAT versus RPAT. These were $\operatorname{IR} \beta$ (greater abundant in RPAT, $P=0.0032$, specifically on $\mathrm{d}+21$ and +100 ; Figure $3 \mathrm{~A}$ ), FAS (greater abundant in RPAT, $P=0.003$, specifically on $\mathrm{d}-42$ and +100 ; Figure $3 \mathrm{D}$ ), AMPK (greater phosphorylated in RPAT, $P<0.0001$, specifically on $\mathrm{d}-42,+1$, and +21 ; Figure 3E), mTOR (greater phosphorylated in SCAT, $P=0.0128$, specifically on d +100 ; Figure $3 \mathrm{G}$ ), Akt (greater phosphorylated in RPAT, $P<0.0001$, specifically on all analyzed days; Figure 3H), and HSL (greater phosphorylated in RPAT, $P=0.0484$; Figure $3 \mathrm{~K})$. Further target proteins did not show significant differences between SCAT and RPAT regarding their 
expression (PI3K, PKC $\zeta$, and GLUT4) or phosphorylation (PDE3B). The expression or phosphorylation of the following target proteins were significantly affected by the progression of the periparturient period: IR $\beta$ expression $(P<0.0001$; Figure $3 \mathrm{~A}), \mathrm{PKC} \zeta$ expression $(P<0.0001$; Figure 3C), FAS expression $(P<0.0001$; Figure 3D), AMPK phosphorylation $(P=0.0004$; Figure 3E), GLUT4 expression $(P<0.0001$; Figure $3 \mathrm{~F})$, mTOR phosphorylation $(P=0.0002$; Figure $3 \mathrm{G})$, Akt phosphorylation $(P<0.0001$; Figure $3 \mathrm{H})$, PDE3B phosphorylation $(P=0.0021$; Figure $3 \mathrm{~J})$, and HSL phosphorylation $(P<0.0001$; Figure $3 \mathrm{~K})$. The IR $\beta$, PKC $\zeta$, FAS, GLUT4, mTOR, Akt, and PD3B were mainly downregulated on days closer to calving, whereas AMPK and HSL were upregulated on days closer to calving. The only target protein that did not show significant time-related differences in its expression was PI3K. Finally, all protein expression and phosphorylation data (including in vitro) were confirmed to be free of significant dietary influences $(P>0.05$ in all proteins in both tissues).

\section{In Vitro Insulin Response of SCAT and RPAT}

Insulin response, in terms of the response observed at the extent of phosphorylation in the anti-lipolytic insulin signaling pathway given to a standard insulin stimulation, showed a slightly different pattern between the 2 target proteins. The Akt phosphorylation was stimulated in RPAT on all studied days and in SCAT on $\mathrm{d}+21$. The extent of Akt phosphorylation was particularly prominent on $\mathrm{d}-42(P=0.0266)$ and $\mathrm{d}+1$ $(P=0.0022)$ in RPAT, reaching 2.09 and 2.26 times greater phosphorylation, respectively, in insulin treated versus control explants (Figure 4A). At later postpartum time points, insulin stimulation still triggered a greater phosphorylation in RPAT, compared with control RPAT explants, but the extent of phosphorylation was less than on the earlier 2 sampling days (1.33 times greater on $\mathrm{d}+21, P=0.0428$; and 1.46 times greater on $\mathrm{d}+100, P=0.0227)$. Comparing the 2 adipose tissue depots, SCAT appeared to be less responsive to the stimulation than RPAT, showing no significant elevation in Akt phosphorylation on $\mathrm{d}-42,+1$, and +100 (Figure 4A).

The applied insulin stimulation decreased HSL phosphorylation in RPAT on d -42 (0.80-fold, $P=0.0028)$, +1 (0.70-fold, $P=0.0014)$, and +100 (0.68-fold, $P$ $=0.0001)$, but not on $\mathrm{d}+21$, compared with control explants (Figure 4B). The SCAT did not show any significant decrease of HSL phosphorylation on $\mathrm{d}-42$, +1 , and +21 , but responded on $\mathrm{d}+100$ (0.85-fold, $P=$
0.0461). Based on the phosphorylation pattern of HSL, SCAT demonstrated a less prominent response to the insulin stimulus, with fewer time points featuring any decrease and also a lesser extent of decrease, compared with RPAT (Figure 4B).

\section{DISCUSSION}

The homeorhetic adaptation of the insulin-glucose system in dairy cows accounts for low insulin and low glucose concentrations during early lactation to ensure glucose flux toward the mammary gland. During this time energy metabolism of the cow must be adjusted to the changes in glucose availability and thereby in energy flux. Insulin-mediated glucose uptake in adipose tissue is generally limited in dairy cows, compared with nonruminants, since the primary substrate used for fatty acid synthesis is acetate (Brockman and Laarveld, 1986). Due to the evolutionary adaptation to low glucose and high short-chain fatty acid availability, insulin action might have less stimulatory effect on glucose metabolism but has a greater effect on driving lipid and protein metabolism in a tissue-specific manner in ruminants (Vernon, 1989). Insulin signal transduction at a post-receptor step is affected by adaptive mechanisms, most likely downstream of PI3K (Vernon, 1989; Sasaki, 2002). Adipose tissues are known to be energy stores that can be used in times of energy scarcity; however, the molecular adaptation at the onset of lactation in these tissues is not well understood. The aim of this study was to evaluate the intrinsic protein expression pattern and extent of phosphorylation of key components of the insulin signaling pathway in subcutaneous and retroperitoneal adipose tissues of periparturient dairy cows. Furthermore, ex vivo incubations were conducted to assess adipose tissue response to insulin (i.e., changes in protein phosphorylation as an effect of a standard insulin stimulus) at different time points during the course of the periparturient period.

Intrinsically, at d -42 RPAT had greater Akt, phospho-AMPK, and FAS expression compared with SCAT as shown in Figure 3. Further, RPAT expressed a stronger response to the physiological changes at the onset of lactation, which clearly confirmed that RPAT is equipped to be metabolically more flexible than SCAT, in line with previous work (Locher et al., 2011; Kenéz et al., 2015). The following observations further support this assumption. Insulin receptor as first key step of the signaling cascade was greater expressed in RPAT at $d+21$ and +100 , and the extent of phosphorylation of Akt, which is a central hub in insulin signaling, was constitutively greater compared with SCAT. Extent of 
Circulating insulin

$\downarrow$ activates

A Insulin receptor, $\beta$ subunit

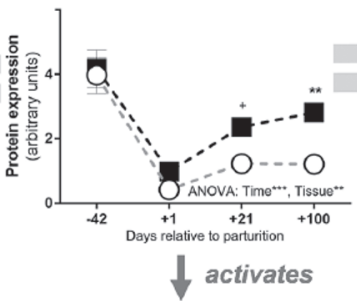

B

Phosphatidylinositol 3-kinase

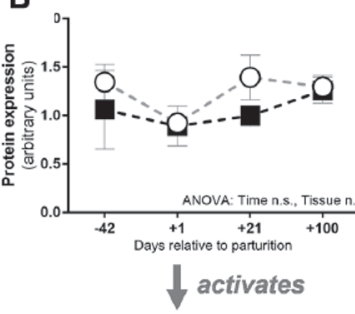

C

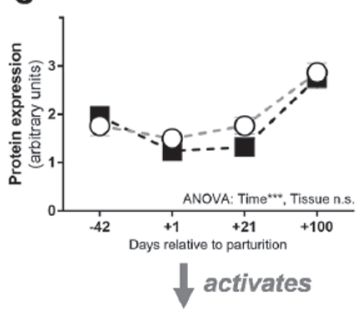

Fatty acid synthase

D

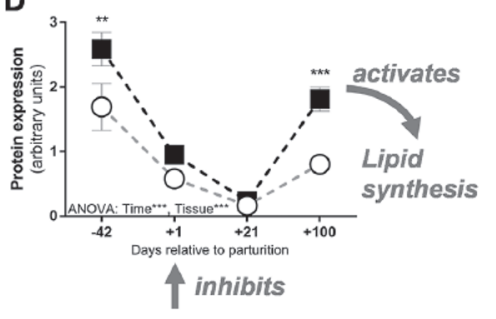

E AMP-activated protein kinase

E Phosphorylated

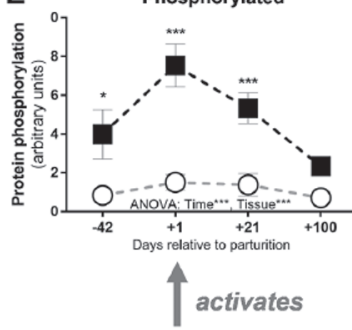

Decreased cellular energy availability
Glucose uptake
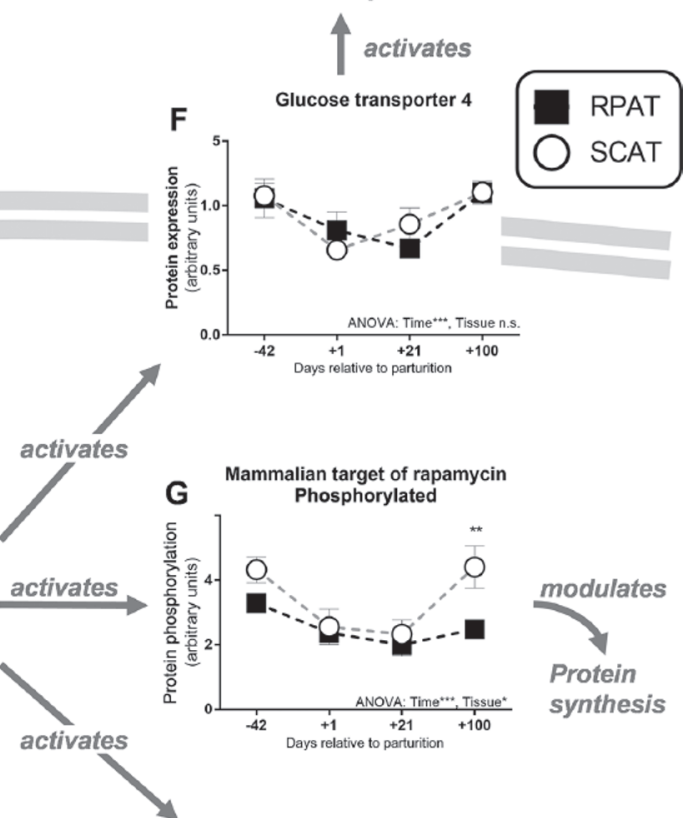

H Protein kinase B (Akt)

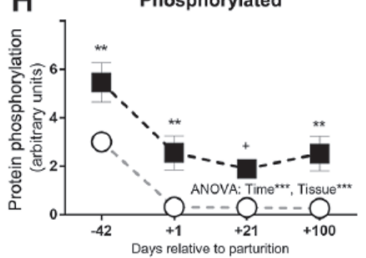

$\downarrow$ activates
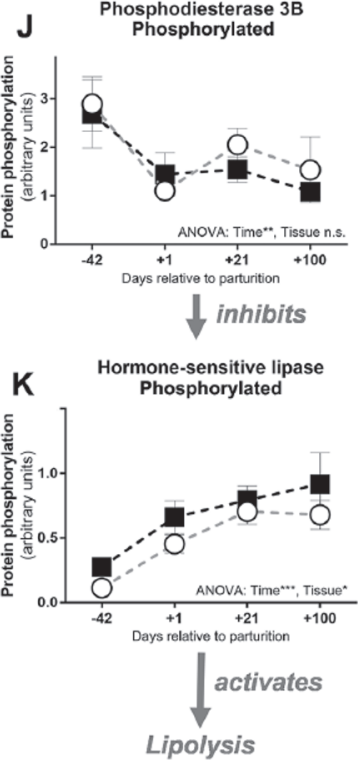

Figure 3. Protein expression and extent of phosphorylation of key components of the insulin signaling pathway in subcutaneous (SCAT) and retroperitoneal (RPAT) adipose tissues of Holstein cows at different days before and after parturition. (A) Insulin receptor $\beta$ subunit expression, (B) phosphatidylinositol 3-kinase expression, (C) protein kinase C $\zeta$ expression, (D) fatty acid synthase expression, (E) AMP-activated protein kinase phosphorylation, $(\mathrm{F})$ glucose transporter 4 expression, $(\mathrm{G})$ mammalian target of rapamycin phosphorylation, $(\mathrm{H})$ protein kinase B phosphorylation, $(\mathrm{J})$ phosphodiesterase 3B phosphorylation, and (K) hormone-sensitive lipase phosphorylation. Effects of tissue (SCAT vs. RPAT) and time (days related to calving) were tested by 2 -way repeated-measures ANOVA with Bonferroni's post-test $\left(+P \leq 0.1,{ }^{*} P \leq 0.05, * * P \leq\right.$ $0.01, * * * P \leq 0.001)$. Means $\pm \mathrm{SEM}, \mathrm{n}=20$. 
phosphorylation was assessed to indicate activation of the respective enzymes (Elkins and Spurlock, 2009; Locher et al., 2015; De Koster et al., 2018). Intriguingly, extent of phosphorylation of mTOR, a serine-threonine kinase regulating translation processes, was lower in RPAT, indicating a diminished capacity for protein synthesis, particularly on $d+100$. Proteins synthesized in adipose tissues are mainly enzymes, receptors, and a large number of adipokines, which are endocrine peptide signals regulating whole body homeostasis (Trayhurn et al., 2006; Mellouk et al., 2017). In fact, comparing the tissue abundance of adiponectin, one of the most abundant adipokines, between multiple subcutaneous and visceral adipose depots revealed the lowest con-
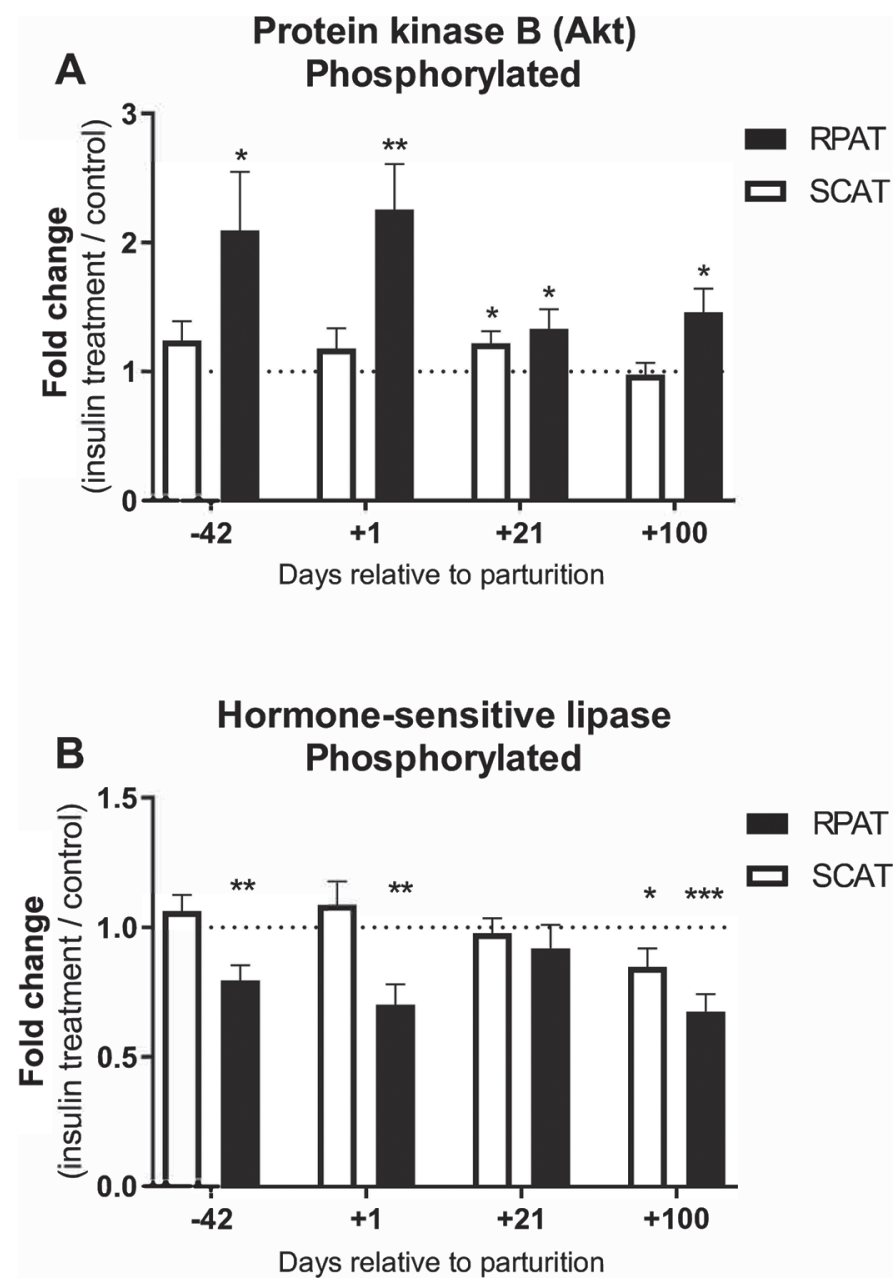

Figure 4. In vitro insulin response in subcutaneous (SCAT) and retroperitoneal (RPAT) adipose tissue explants of Holstein cows at different days before and after parturition. (A) Protein kinase B (Akt) extent of phosphorylation, and (B) hormone-sensitive lipase extent of phosphorylation. Fold-change (insulin treated/untreated) values were tested against the theoretical value of 1.0 by a 1 -sample $t$-test $\left({ }^{*} P \leq\right.$ $\left.0.05,{ }^{* *} P \leq 0.01,{ }^{* * *} P \leq 0.001\right)$. Means \pm SEM, $\mathrm{n}=20$. centration of adiponectin in RPAT in periparturient cows (Singh et al., 2014). Besides protein synthesis, insulin acts on lipid metabolism by stimulating fatty acid synthesis and inhibiting lipolysis. Both pathways are activated in periparturient cows to balance energy homeostasis and to maintain adipose tissue structure (McNamara, 1989; Kenéz et al., 2015; McNamara et al., 2016); however, RPAT expressed a greater level of FAS expression and enhanced extent of phosphorylation of HSL compared with SCAT. Because low plasma insulin was a major contributor in upregulating lipolysis and downregulating lipogenesis during early lactation, this resulted in the commonly seen plasma NEFA peak (Chilliard et al., 2000). However, additional evidence from the literature showed differences in regulation of lipolytic and lipogenic pathways between subcutaneous and visceral adipose tissue depots. Circulating fatty acid profiles of transition cows were found to be more closely associated with those of abdominal fat depots, compared with SCAT, suggesting that abdominal fat was preferentially mobilized (Hostens et al., 2012). Additionally, De Koster et al. (2016) showed that BCS has an effect on whether subcutaneous or abdominal adipose depots are preferentially mobilized as an effect of lipolytic signals. These depot-specific differences could be modulated by differential extents of HSL phosphorylation between depots, observed in the present study and in previous work (Locher et al., 2011; Kenéz et al., 2015). Alternatively, this could be based on the fact that abdominal adipose depots provide a quantitatively greater fat pool, estimated to be approximately 3 times larger than subcutaneous fat depots (Raschka et al., 2016; Ruda et al., 2019).

The cellular energy sensor AMPK, an AMP-dependent kinase that is activated by energy depletion (Omar et al., 2009; Locher et al., 2012), showed a distinctly different phosphorylation pattern between RPAT and SCAT, indicating an intense activation of this sensor in RPAT at the onset of lactation. The AMPK appeared to be the prominent molecular target to sense the energy shift to the mammary gland in early lactation (Kuhla et al., 2009; McFadden and Corl, 2009). RPAT with its lipolytic capacity was identified as key tissue in this metabolic regulation in periparturient dairy cows. A high activation of the cellular energy sensor AMPK, and concomitantly, an enhanced extent of HSL phosphorylation confirmed the greater lipolytic capacity previously described in this adipose tissue depot (Locher et al., 2011, 2012). Further, greater extent of AMPK phosphorylation was observed when PKC $\zeta$ expression was relatively lower, particularly on $\mathrm{d}+1$ and +21 . This highlights an important biochemical link between glucose uptake and excessive free fatty acids release, as follows. In times of reduced insulin sensi- 
tivity, low cellular glucose availability restrains energy gaining processes, reflected by high AMPK phosphorylation, and at the same time low glucose availability limits substrate (i.e., glycerol 3-phosphate) supply for cellular free fatty acids re-esterification, which can be seen as a contributor to excessive lipid mobilization, as discussed previously (Kinoshita et al., 2016a).

It should be noted that the dynamic changes of key components of the insulin signaling cascade observed postpartum occurred without concomitant changes in serum insulin concentration. In fact, serum insulin concentration remained decreased during the postpartum period, whereas proteins of the insulin signaling pathway were generally decreased first and increased later in their expression or extent of phosphorylation. This draws attention to insulin-independent modulatory mechanisms that have an effect on balancing insulin sensitivity in adipose tissue, possibly due to interactions with ceramides (Rico et al., 2018) or with various other compounds that belong to the multifaceted group of signaling lipids (Kenéz et al., 2016). Even if the exact signaling mechanisms are yet to be cleared, it should be noted that the observed effects (i.e., decreased protein expression or phosphorylation early postpartum) are in line with the overall aim of homeorhetic adaptation, which is to reduce glucose uptake on the periphery and to allow lipid mobilization as fuel for energy-consuming processes (Drackley, 1999).

Adipose tissue response to insulin over the course of the transition period was reported to be affected by genetic background (Zachut et al., 2013). However, the responsible mechanisms are presumably mediated at a post-transcriptional level, based on the lack of remarkable adaptive changes in mRNA expression of insulin signaling elements (Sadri et al., 2010) and the dynamic changes in protein expression and extent of phosphorylation during the periparturient period that were observed previously (Mann et al., 2016) and similarly in the present study. Further mechanisms might include changes in receptor affinity and enzyme activity; however, these were not assessed in our study. To summarize, it can be assumed that insulin effects can be maintained despite low plasma concentrations, by adjustments of cellular signaling machinery elements, and these effects can be depot specific. The distinctly greater response of RPAT was also confirmed by the ex vivo assay. When isolated adipose tissue samples were stimulated by a physiological dose of insulin, RPAT expressed a strong increase in the extent of Akt phosphorylation. Consequently, extent of HSL phosphorylation, which was shown to be indicative for lipolytic function (Kenéz et al., 2015; De Koster et al., 2018), was more strongly inhibited by insulin in RPAT in this ex vivo stimulation experiment. This observation matched the simultaneously greater extent of HSL phosphorylation in biopsy samples of the same cows, which can be interpreted as a greater flexibility of RPAT to adapt to changing physiological conditions. This is in line with visceral adipose tissues being considered to be more flexible and faster accessible pools of energy deposition and mobilization in humans, compared with SCAT (Romao et al., 2013; Fried et al., 2015).

\section{CONCLUSIONS}

Studying the molecular modulation of insulin signaling and insulin response suggested that both subcutaneous and retroperitoneal adipose tissue depots contributed to the periparturient homeorhetic adaptation, although the extent of this adaptation most likely differed based on the observed depot-specific variation. Consequently, adipose tissue endocrine response and adipose energy metabolism could contribute to whole-body adaptation to the onset of lactation in dairy cows in a depot-specific manner. A disruption in depot-specific pathways may be detrimental for homeorhetic adaptation to lactation, exposing cows to a risk of failure in maintaining energy homeostasis and to a risk of developing productionrelated metabolic disorders.

\section{ACKNOWLEDGMENTS}

The authors thank the staff of the Institute of Animal Nutrition, Friedrich-Loeffler-Institute (Braunschweig, Germany) for their assistance during animal handling and sample collection.

\section{REFERENCES}

Bradford, B. J., K. Yuan, J. K. Farney, L. K. Mamedova, and A. J. Carpenter. 2015. Invited review: Inflammation during the transition to lactation: New adventures with an old flame. J. Dairy Sci. 98:6631-6650. https://doi.org/10.3168/jds.2015-9683.

Brockman, R. P., and B. Laarveld. 1986. Hormonal regulation of metabolism in ruminants; a review. Livest. Prod. Sci. 14:313-334. https://doi.org/10.1016/0301-6226(86)90012-6.

Chilliard, Y., A. Ferlay, Y. Faulconnier, M. Bonnet, J. Rouel, and F. Bocquier. 2000. Adipose tissue metabolism and its role in adaptations to undernutrition in ruminants. Proc. Nutr. Soc. 59:127-134. https://doi.org/10.1017/S002966510000015X

De Koster, J., R. K. Nelli, C. Strieder-Barboza, J. de Souza, A. L. Lock, and G. A. Contreras. 2018. The contribution of hormone sensitive lipase to adipose tissue lipolysis and its regulation by insulin in periparturient dairy cows. Sci. Rep. 8. https://doi.org/ 10.1038/s41598-018-31582-4.

De Koster, J., W. Van den Broeck, L. Hulpio, E. Claeys, M. Van Eetvelde, K. Hermans, M. Hostens, V. Fievez, and G. Opsomer. 2016. Influence of adipocyte size and adipose depot on the in vitro lipolytic activity and insulin sensitivity of adipose tissue in dairy cows at the end of the dry period. J. Dairy Sci. 99:2319-2328. https:// doi.org/10.3168/jds.2015-10440.

De Koster, J. D., and G. Opsomer. 2013. Insulin resistance in dairy cows. Vet. Clin. North Am. Food Anim. Pract. 29:299-322. https: //doi.org/10.1016/j.cvfa.2013.04.002. 
Drackley, J. K. 1999. Biology of dairy cows during the transition period: The final frontier? J. Dairy Sci. 82:2259-2273. https://doi .org/10.3168/jds.S0022-0302(99)75474-3.

Drackley, J. K., T. R. Overton, and G. N. Douglas. 2001. Adaptations of glucose and long-chain fatty acid metabolism in liver of dairy cows during the periparturient period. J. Dairy Sci. 84:E100-E112. https://doi.org/10.3168/jds.S0022-0302(01)70204-4.

Elkins, D. A., and D. M. Spurlock. 2009. Phosphorylation of perilipin is associated with indicators of lipolysis in Holstein cows. Horm. Metab. Res. 41:736-740. https://doi.org/10.1055/s-0029-1225359.

Fried, S. K., M.-J. Lee, and K. Karastergiou. 2015. Shaping fat distribution: New insights into the molecular determinants of depotand sex-dependent adipose biology: Depot- and sex-dependent adipose biology. Obesity (Silver Spring) 23:1345-1352. https://doi .org/10.1002/oby.21133.

Holm, C., T. Østerlund, H. Laurell, and J. A. Contreras. 2000. Molecular mechanisms regulating hormone-sensitive lipase and lipolysis. Annu. Rev. Nutr. 20:365-393.

Hostens, M., V. Fievez, J. L. M. R. Leroy, J. Van Ranst, B. Vlaeminck, and G. Opsomer. 2012. The fatty acid profile of subcutaneous and abdominal fat in dairy cows with left displacement of the abomasum. J. Dairy Sci. 95:3756-3765. https://doi.org/10.3168/ jds.2011-5092.

Ingvartsen, K. L. 2006. Feeding- and management-related diseases in the transition cow. Anim. Feed Sci. Technol. 126:175-213. https:/ /doi.org/10.1016/j.anifeedsci.2005.08.003.

Ingvartsen, K. L., R. J. Dewhurst, and N. C. Friggens. 2003. On the relationship between lactational performance and health: Is it yield or metabolic imbalance that cause production diseases in dairy cattle? A position paper. Livest. Prod. Sci. 83:277-308.

Ji, P., J. K. Drackley, M. J. Khan, and J. J. Loor. 2014. Inflammationand lipid metabolism-related gene network expression in visceral and subcutaneous adipose depots of Holstein cows. J. Dairy Sci 97:3441-3448. https://doi.org/10.3168/jds.2013-7296.

Kahn, R. C. 1978. Insulin resistance, insulin insensitivity, and insulin unresponsiveness: A necessary distinction. Metabolism 27:18931902. https://doi.org/10.1016/s0026-0495(78)80007-9.

Kenéz, Á., S. Dänicke, U. Rolle-Kampczyk, M. von Bergen, and K. Huber. 2016. A metabolomics approach to characterize phenotypes of metabolic transition from late pregnancy to early lactation in dairy cows. Metabolomics 12. https://doi.org/10.1007/s11306-016 $-1112-8$.

Kenéz, A., L. Locher, J. Rehage, S. Dänicke, and K. Huber. 2014. Agonists of the G protein-coupled receptor 109A-mediated pathway promote antilipolysis by reducing serine residue 563 phosphorylation of hormone-sensitive lipase in bovine adipose tissue explants. J. Dairy Sci. 97:3626-3634. https://doi.org/10.3168/jds .2013-7662.

Kenéz, Á., R. Tienken, L. Locher, U. Meyer, A. Rizk, J. Rehage, S. Dänicke, and K. Huber. 2015. Changes in lipid metabolism and $\beta$-adrenergic response of adipose tissues of periparturient dairy cows affected by an energy-dense diet and nicotinic acid supplementation. J. Anim. Sci. 93:4012-4022. https://doi.org/10.2527/ jas.2014-8833.

Kinoshita, A., Á. Kenéz, L. Locher, U. Meyer, S. Dänicke, J. Rehage, and K. Huber. 2016a. Insulin signaling in liver and adipose tissues in periparturient dairy cows supplemented with dietary nicotinic acid. PLoS One 11:e0147028. https://doi.org/10.1371/journal .pone.0147028.

Kinoshita, A., L. Locher, R. Tienken, U. Meyer, S. Dänicke, J. Rehage, and K. Huber. 2016b. Associations between Forkhead Box O1 (FoxO1) expression and indicators of hepatic glucose production in transition dairy cows supplemented with dietary nicotinic acid. PLoS One 11:e0146670. https://doi.org/10.1371/journal .pone.0146670.

Kuhla, B., D. Albrecht, S. Kuhla, and C. C. Metges. 2009. Proteome analysis of fatty liver in feed-deprived dairy cows reveals interaction of fuel sensing, calcium, fatty acid, and glycogen metabolism. Physiol. Genomics 37:88-98. https://doi.org/10.1152/ physiolgenomics.90381.2008.
Locher, L., S. Häussler, L. Laubenthal, S. P. Singh, J. Winkler, A Kinoshita, Á. Kenéz, J. Rehage, K. Huber, H. Sauerwein, and S. Dänicke. 2015. Effect of increasing body condition on key regulators of fat metabolism in subcutaneous adipose tissue depot and circulation of nonlactating dairy cows. J. Dairy Sci. 98:1057-1068. https://doi.org/10.3168/jds.2014-8710.

Locher, L. F., N. Meyer, E.-M. Weber, J. Rehage, U. Meyer, S. Dänicke, and K. Huber. 2011. Hormone-sensitive lipase protein expression and extent of phosphorylation in subcutaneous and retroperitoneal adipose tissues in the periparturient dairy cow. J. Dairy Sci. 94:4514-4523. https://doi.org/10.3168/jds.2011-4145.

Locher, L. F., J. Rehage, N. Khraim, U. Meyer, S. Dänicke, K. Hansen, and K. Huber. 2012. Lipolysis in early lactation is associated with an increase in phosphorylation of adenosine monophosphate-activated protein kinase (AMPK) $\alpha 1$ in adipose tissue of dairy cows. J. Dairy Sci. 95:2497-2504. https://doi.org/10.3168/jds.2011-4830.

Mann, S., D. V. Nydam, A. Abuelo, F. A. Leal Yepes, T. R. Overton and J. J. Wakshlag. 2016. Insulin signaling, inflammation, and lipolysis in subcutaneous adipose tissue of transition dairy cows either overfed energy during the prepartum period or fed a controlled-energy diet. J. Dairy Sci. 99:6737-6752. https://doi.org/10 $.3168 /$ jds.2016-10969.

McArt, J. A. A., D. V. Nydam, and G. R. Oetzel. 2012. Epidemiology of subclinical ketosis in early lactation dairy cattle. J. Dairy Sci. 95:5056-5066. https://doi.org/10.3168/jds.2012-5443.

McFadden, J. W., and B. A. Corl. 2009. Activation of AMP-activated protein kinase (AMPK) inhibits fatty acid synthesis in bovine mammary epithelial cells. Biochem. Biophys. Res. Commun. 390:388-393. https://doi.org/10.1016/j.bbrc.2009.09.017.

McNamara, J. P. 1989. Regulation of bovine adipose tissue metabolism during lactation. 5. Relationships of lipid synthesis and lipolysis with energy intake and utilization. J. Dairy Sci. 72:407-418. https://doi.org/10.3168/jds.S0022-0302(89)79122-0.

McNamara, J. P., and J. K. Hillers. 1986. Regulation of bovine adipose tissue metabolism during lactation. 2. Lipolysis response to milk production and energy intake. J. Dairy Sci. 69:3042-3050.

McNamara, J. P., K. Huber, and A. Kenéz. 2016. A dynamic, mechanistic model of metabolism in adipose tissue of lactating dairy cattle. J. Dairy Sci. 99:5649-5661. https://doi.org/10.3168/jds $.2015-9585$.

Mellouk, N., C. Rame, J. L. Touzé, E. Briant, L. Ma, D. Guillaume, D. Lomet, A. Caraty, T. Ntallaris, P. Humblot, and J. Dupont. 2017. Involvement of plasma adipokines in metabolic and reproductive parameters in Holstein dairy cows fed with diets with differing energy levels. J. Dairy Sci. 100:8518-8533. https://doi.org/10.3168/ jds.2017-12657.

Omar, B., E. Zmuda-Trzebiatowska, V. Manganiello, O. Göransson, and E. Degerman. 2009. Regulation of AMP-activated protein kinase by cAMP in adipocytes: Roles for phosphodiesterases, protein kinase B, protein kinase A, Epac and lipolysis. Cell. Signal. 21:760-766. https://doi.org/10.1016/j.cellsig.2009.01.015.

Ospina, P. A., J. A. McArt, T. R. Overton, T. Stokol, and D. V. Nydam. 2013. Using nonesterified fatty acids and $\beta$-hydroxybutyrate concentrations during the transition period for herd-level monitoring of increased risk of disease and decreased reproductive and milking performance. Vet. Clin. North Am. Food Anim. Pract. 29:387-412. https://doi.org/10.1016/j.cvfa.2013.04.003.

Raschka, C., L. Ruda, P. Wenning, C.-I. von Stemm, C. Pfarrer, K Huber, U. Meyer, S. Dänicke, and J. Rehage. 2016. In vivo determination of subcutaneous and abdominal adipose tissue depots in German Holstein dairy cattle. J. Anim. Sci. 94:2821-2834. https:/ /doi.org/10.2527/jas.2015-0103.

Rico, J. E., W. A. Myers, D. J. Laub, A. N. Davis, Q. Zeng, and J. W McFadden. 2018. Hot topic: Ceramide inhibits insulin sensitivity in primary bovine adipocytes. J. Dairy Sci. 101:3428-3432. https: //doi.org/10.3168/jds.2017-13983.

Romao, J. M., W. Jin, M. He, T. McAllister, and L. L. Guan. 2013 Elucidation of molecular mechanisms of physiological variations between bovine subcutaneous and visceral fat depots under dif- 
ferent nutritional regimes. PLoS One 8:e83211. https://doi.org/10 .1371/journal.pone.0083211.

Ruda, L., C. Raschka, K. Huber, R. Tienken, U. Meyer, S. Dänicke, and J. Rehage. 2019. Gain and loss of subcutaneous and abdominal fat depot mass from late pregnancy to 100 days in milk in German Holsteins. J. Dairy Res. 86:296-302.

Sadri, H., R. M. Bruckmaier, H. R. Rahmani, G. R. Ghorbani, I. Morel, and H. A. van Dorland. 2010. Gene expression of tumour necrosis factor and insulin signalling-related factors in subcutaneous adipose tissue during the dry period and in early lactation in dairy cows. J. Anim. Physiol. Anim. Nutr. (Berl.) 94:e194-e202. https://doi.org/10.1111/j.1439-0396.2010.01005.x.

Sasaki, S. 2002. Mechanism of insulin action on glucose metabolism in ruminants. Anim. Sci. J. 73:423-433. https://doi.org/10.1046/j .1344-3941.2002.00059.x.

Singh, S. P., S. Häussler, J. F. L. Heinz, S. H. Akter, B. Saremi, U. Müller, J. Rehage, S. Dänicke, M. Mielenz, and H. Sauerwein. 2014. Lactation driven dynamics of adiponectin supply from different fat depots to circulation in cows. Domest. Anim. Endocrinol. 47:35-46. https://doi.org/10.1016/j.domaniend.2013.12.001.

Tienken, R., S. Kersten, J. Frahm, U. Meyer, L. Locher, J. Rehage, K. Huber, Á. Kenéz, H. Sauerwein, M. Mielenz, and S. Dänicke. 2015. Effects of an energy-dense diet and nicotinic acid supplementation on production and metabolic variables of primiparous or multiparous cows in periparturient period. Arch. Anim. Nutr. 69:319-339. https://doi.org/10.1080/1745039X.2015.1073002.

Trayhurn, P., C. Bing, and I. S. Wood. 2006. Adipose tissue and adipokines - Energy regulation from the human perspective. J. Nutr. 136:1935S-1939S. https://doi.org/10.1093/jn/136.7.1935S.

Vernon, R. G. 1989. Endocrine control of metabolic adaptation during lactation. Proc. Nutr. Soc. 48:23-32. https://doi.org/10.1079/ PNS19890006.

White, M. F. 1997. The insulin signalling system and the IRS proteins. Diabetologia 40:S2-S17.

Zachut, M., H. Honig, S. Striem, Y. Zick, S. Boura-Halfon, and U. Moallem. 2013. Periparturient dairy cows do not exhibit hepatic insulin resistance, yet adipose-specific insulin resistance occurs in cows prone to high weight loss. J. Dairy Sci. 96:5656-5669. https: //doi.org/10.3168/jds.2012-6142.

\section{ORCIDS}

Á. Kenéz @ https://orcid.org/0000-0002-9041-3452

K. Huber @ https://orcid.org/0000-0002-1293-8472 